\title{
Status Quo and Development Trend of Continuing Medical Education of Rural Doctors under "Internet+" in China
}

\author{
Meng Zhao', Geng Zhao², Lei Zhang1 \\ ${ }^{1}$ Department of Administrative Theory, School of Humanities and Law, Northeastern University, Shenyang, China \\ ${ }^{2}$ Department of Public Administration Humanities and Law, Northeastern University, Shenyang, China \\ Email: beyunbu@126.com,249960729@qq.com
}

How to cite this paper: Zhao, M., Zhao, G. and Zhang, L. (2019) Status Quo and Development Trend of Continuing Medical Education of Rural Doctors under "Internet+" in China. Journal of Service Science and Management, 12, 542-548.

https://doi.org/10.4236/jssm.2019.124037

Received: April 26, 2019

Accepted: June 22, 2019

Published: June 25, 2019

Copyright () 2019 by author(s) and Scientific Research Publishing Inc. This work is licensed under the Creative Commons Attribution International License (CC BY 4.0). http://creativecommons.org/licenses/by/4.0/

\begin{abstract}
Distance teaching based on "Internet+" is vital for rural doctors who play an important part in public health services and basic medical services to continue medical education and enrich and improve their theoretical knowledge and professional ability, so continuing medical education of rural doctors under "Internet+" is an important reform, but it has some weaknesses, therefore some recommendations were made in this research specific to its problems and development trend.
\end{abstract}

\section{Keywords}

Rural Doctors, Internet+, Continuing Medical Education, Public Health

\section{Introduction}

Due to the large population in China, there is an imbalance in the allocation of medical and health resources in developed and underdeveloped areas. As the core of the whole health system, public health services and basic medical services are the most common and familiar to the public. However, as an important part of the rural health team, rural doctors are directly responsible for the basic medical care, prevention, health care and health education of 800 million farmers in China, so they play an important role in public health services [1]. Specific to the rural medical condition and the problems in training of rural doctors in the western region, it is of positive practical significance to explore a more scientific, rational, practical and feasible training mode for rural doctors to improve the overall quality and professional ability of rural doctors more effectively, promote the consolidation and development of new rural cooperative medical system and 
construct harmonious rural communities.

In July 2015, the State Council issued the Guiding Opinions of the State Council on Actively Promoting "Internet+" Actions to clarify the concept that "Internet+" is to deeply integrate the innovative achievements of the Internet with all fields of the economy and society to promote technological progress, efficiency and organizational change, improve the creativity and productivity in the real economy and form a broader new form of economic and social development with the Internet as infrastructure and innovation element [2]. The State Council proposed in the development goal that Internet applications should be enriched in the fields of health care and education and at the same time suggested that the Internet should be taken as the infrastructure and innovation element to explore the new supply mode of education services. Based on this context and the trend of integration and development of the Internet and traditional continuing education industry, the continuing medical education of rural doctors is gradually stepping into the era of "Internet+" and the integration models of continuing education of rural doctors based on the Internet platform are also emerging constantly [3].

\section{Characteristics of Continuing Medical Education of Rural Doctors under "Internet+"}

A key concept of the Internet is that it was not designed for just one application, but as a general infrastructure on which new applications could be conceived, as illustrated later by the emergence of the World Wide Web [4]. The changes in continuing medical education brought about by "Internet+" have broken through the scope of technology, which are actually more those in concept and mode. The characteristics of "Internet+" can be summarized into four aspects, namely new infrastructure, new production factor, new social space and new industry form [5] [6]. However, it also has unique significance. First, it breaks the coupling between information and other elements through data connection to enhance mobility. Second, it forms new collaboration through data connection. "Internet+" continuing medical education represents not only the innovation of educational technology but also the construction of new educational ecosystem with the Internet as infrastructure and innovation element [7]. Based on the online education information platform, "Internet+" unifies medical college education, hospital continuing education and health management education institution so that they can support the continuing education of rural doctors together.

\section{Status Quo of Continuing Medical Education under "Internet+"}

Continuing medical education is the third brand new stage refers to medical students' experience of basic education in medical colleges and medical education after graduation, which is the longest continuous period in the whole continuum of medical education, is a lifelong medical education focusing on learning new theories, new knowledge, new technologies and new methods [8] [9]. 
Under "Internet+", there have been many new changes in continuing medical education. For example, in terms of teaching resources, the platforms such as Massive Open Online Courses (MOOC), Coursera joined by Fudan University and Shanghai Jiaotong University, XuetangX and icourse163 break the traditional face-to-face teaching model and integrate the concepts of online learning, big data analysis and mobile Internet to achieve the most extensive sharing of high-quality teaching resources on the Internet platform [10]. In terms of the reform of teaching methods, the novel "Internet+ flipping classroom" proposed in recent years is close to the life in the network era, which fully reflects the personalization of learning, for the difficult knowledge points can be solved through repeated video watching, forum discussion or targeted teaching in the classroom and online homework can test the learning effects in a timely manner, improve learning efficiency and attitude and enhance learning initiative [11]. In this model, medical colleges connect to the network platform and provide remote medical basic education to the rural doctors on the other end of the network anytime and anywhere in the form of online courses. Medical so they realize networking of offline medical teaching through online courses, such as the online course alliance on zhihuishu.com.

\section{Strengths and Weaknesses of Continuing Medical Education of Rural Doctors under "Internet+"}

\subsection{Strengths}

Continuing medical education under "Internet+" has following prominent advantages. First, it has a low threshold for learners, who all have the opportunity to participate in learning regardless of their location, level of knowledge storage and education background, as long as certain hardware requirements are met, so it is the objective condition suitable for the training and learning of rural doctors. Second, it has a flexible curriculum. The flexibility here includes two meanings. On the one hand, the learning time is flexible so that rural doctors can better balance the contradiction of time between work and learning and use fragmented time for learning; on the other hand, due to the flexible learning content, rural doctors can choose courses according to their needs for new technology and knowledge. Third, rural doctors can choose learning contents from the rich teaching resources of various learning platforms and make adjustment in time, who no longer need to accept the cramming method of teaching. Fourth, there are rich course contents. Hospitals are the main places for rural doctors to learn practical skills, where the actual cases are the most vivid learning resources for them [12] [13]. In the "Internet+" era, the hospital information system (HIS) interconnects with the continuing education network platform through standard interfaces and doctors or educators share teaching cases and electronic medical records (EMR) to the continuing education platform through HIS so that database of teaching cases and EMR can be constructed to realize the sharing of teaching resources. Due to the function of interactive discussion (such as forum, 
online meeting and remote video) provided by the platform, case-based and EMR practice teaching can be carried out anytime and anywhere, which moves the contents of offline practical learning to the online platform to a certain extent [14].

\subsection{Weaknesses}

According to the existing exploration and practice, there are also some problems and weaknesses of "Internet+" continuing medical education. First, the dropout rate is high. This learning style has high requirements for self-discipline, patience and perseverance of learners due to its great freedom, but some learners cannot complete all courses and drop out. Second, it is difficult to ensure the quality of evaluation and feedback. Most of these courses are subject to online evaluation and feedback, which cannot truly reflect the mastery of knowledge points by the learners due to lack of real-time monitoring and more uncontrollable factors in the examination and evaluation, and in addition the incomplete video watching cannot guarantee that the teaching feedback is objective evaluation [15]. Third, teachers and students cannot achieve face-to-face communication. At present, most rural doctors graduate from junior colleges and have low overall quality, and most courses provide no real-time Q\&A so that teachers and students leave messages to realize Q\&A. In addition, it is difficult for online learning to construct or virtualize real diagnosis and treatment situations, which reduces the authenticity and situationality of diagnosis and treatment and affects the teaching effect and the training of practical skills. The medical discipline has unique features, which require more hands-on operation and practice besides theory teaching, so face-to-face teaching cannot be implemented online [16]. Fourth, there are problems of information security. The hospital realizes case sharing through the information system, which directly faces problems of information security, so the attention should also be paid to the issue of privacy of students and patients [17].

\section{Development Trend and Prospects of Continuing Medical Education of Rural Doctors under "Internet+"}

With the increasingly deepened integration of Internet and continuing education, the continuing education of rural doctors is gradually stepping into the "Internet+" era and the integration models of continuing education of rural doctors based on the Internet platform is also emerging constantly, such as the Training Center for Rural Doctors established jointly by the Ministry of Health and China Medical University and the Education Network for Rural Doctors jointly established by Weihai Health Worker Training School, Weihai Administration of Health and Weihaiwei Hospital [18]. In terms of education platform construction, the embryonic form of the Internet platform for continuing medical education of rural doctors that integrates different parties has emerged and is developing further. According to the Opinions of the General Office of the State 
Council on deepening Coordination of Medical Education and Further Promoting Its Development, it is necessary to strengthen the continuous education of all health workers, improve the learning system of life-long education and vigorously develop distance education to establish cloud platforms for health education and training based on the National Open University of Health Care and supported by China Health Education MOOC Allianc [19] [20]. In addition, in the context of "Internet+", it is necessary to explore the path and model suitable for the development of continuing medical education under "Internet+" in China so as to realize the transformation of all factors from infrastructure to institution and organization.

\section{Conclusions}

Therefore, the following recommendations were made. First, under the high cost of continuing medical education based on the advanced technology of the Internet, the collaboration and cooperation should be strengthened among various industries to construct a new system of continuing medical education to promote the development of the whole industry. Second, the weaknesses of the "Internet+" model should also be identified to actively establish the training model that combines online teaching and face-to-face teaching, autonomous learning and cooperative learning, theoretical learning and practical operation. Third, the advantages of big data in the "Internet+" era can be used to record and analyze learning behavior for more accurate content control and effect analysis of the whole training process so as to achieve the "trainee-centered" continuing medical education model.

As the core of the whole health system, public health services and basic medical services are the most common and familiar to the public. According to international experience, a sound and strong system of basic medical services can enhance service accessibility and equity and lead to higher patient satisfaction, which has the same and even better output and results with fewer resources compared to non-basic medical care [21] [22]. The network information platform integrating "province, county, township and village" can be set up based on the government funds to realize distance teaching of rural doctor through "Internet+", which can provide convenient and quick teaching and management for the further education and on-the-job training of rural doctors. The goal of "basic health services for all" proposed by the Chinese government at the present stage is to build a fair, efficient and high-quality health service system, which is a further extension of the development of primary health care to a higher level [23].

In conclusion, due to the extremely unbalanced economic development in the western region, there is still a gap in the allocation of health resources and rural residents have different health problems, so the training of rural doctors can be carried out in a multi-level and multi-mode manner to meet the health needs of farmers. The above-mentioned training model and management model should be chosen according to local conditions and the on-the-job training of rural 
doctors should be gradually improved to promote the development of rural health cause and truly achieve health and well-being of all people.

\section{Conflicts of Interest}

The authors declare no conflicts of interest regarding the publication of this paper.

\section{References}

[1] Hou, J. and Ke, Y. (2015) Addressing the Shortage of Health Professionals in Rural China: Issues and Progress: Comment on "Have Health Human Resources Become More Equal between Rural and Urban Areas after the New Reform"? International Journal of Health Policy and Management, 4, 327. https://doi.org/10.15171/ijhpm.2015.57

[2] Hu, W.-W. (2016) Internet+ China's Cultural Industries and IPR Protection Concern. 2016 International Conference on Service Science, Technology and Engineering, Suzhou, 14-15 May 2016, 243-246.

[3] Zhao, H. (2017) Exploration of the Three-in-One Mode of Rural Doctors' Internet plus Continuing Education. China Medical Education Technology, 6, 3.

[4] Leiner, B.M., Cerf, V.G., Clark, D.D., et al. (2009) A Brief History of the Internet. ACM SIGCOMM Computer Communication Review, 39, 22-31. https://doi.org/10.1145/1629607.1629613

[5] Wang, L. and Sun, B. (2015) New Trend of Online Education Development in the Context of Internet+ Era-“2015 International Distance Education Development BBS” Review. China Distance Education, No. 12, 12-17.

[6] Shi, H.-B. and Wang, M.-Y. (2016) Analysis on the Influences and Countermeasures of China's Education Reform under the Background of "Internet+". 2016 International Conference on Service Science, Technology and Engineering, Suzhou, 14-15 May 2016.

[7] Wutoh, R., Boren, S.A. and Balas, E.A. (2004) e-Learning: A Review of Internet-Based Continuing Medical Education. Journal of Continuing Education in the Health Professions, 24, 20-30. https://doi.org/10.1002/chp.1340240105

[8] Chen, F., Lui, A.M. and Martinelli, S.M. (2017) A Systematic Review of the Effectiveness of Flipped Classrooms in Medical Education. Medical Education, 51, 585-597. https://doi.org/10.1111/medu.13272

[9] Sutherland, S. and Jalali, A. (2017) Social Media as an Open-Learning Resource in Medical Education: Current Perspectives. Advances in Medical Education and Practice, 8, 369. https://doi.org/10.2147/AMEP.S112594

[10] Shen, J., Ye, M., Wang, Y., et al. (2016) Massive Open Online Course (MOOC) in China: Status Quo, Opportunities, and Challenges. 2016 IEEE Global Engineering Education Conference, Abu Dhabi, 10-13 April 2016, 1106-1108. https://doi.org/10.1109/EDUCON.2016.7474692

[11] Li, G. (2017) A Study on the Blended-Teaching Mode Combining MOOCs and Flipping Classroom in College English Teaching. 7 th International Conference on Education, Management, Information and Mechanical Engineering, Shenyang, 28-30 April 2017, 1272-1278. https://doi.org/10.2991/emim-17.2017.256

[12] Peng, X., Shen, S., Zhang, H., et al. (2017) “The Application of" "Internet+" Model in Medical Education. Chinese Journal of Medical Education Research, 16, 846-851. 
[13] Zhao, H., Li, G. and Feng, W. (2018) Application of "Internet+" in Healthcare. 2018 International Conference on Engineering Simulation and Intelligent Control, Changsha, 24-25 August 2018, 368-371. https://doi.org/10.1109/ESAIC.2018.00093

[14] Wu, Y. and Xia, K. (2017) Analysis of the Current Status and Development of Internet+ Medical Care in China. 9th International Economics, Management and Education Technology Conference, Taiyuan, 12-14 July 2017. https://doi.org/10.2991/iemetc-17.2017.68

[15] Harden, R.M. (2005) A New Vision for Distance Learning and Continuing Medical Education. Journal of Continuing Education in the Health Professions, 25, 43-51. https://doi.org/10.1002/chp.8

[16] Wong, G., Greenhalgh, T. and Pawson, R. (2010) Internet-Based Medical Education: A Realist Review of What Works, for Whom and in What Circumstances. BMC Medical Education, 10, 12. https://doi.org/10.1186/1472-6920-10-12

[17] Tjora, A., Tran, T. and Faxvaag, A. (2005) Privacy vs. Usability: A Qualitative Exploration of Patients' Experiences with Secure Internet Communication with Their General Practitioner. Journal of Medical Internet Research, 7, e15. https://doi.org/10.2196/jmir.7.2.e15

[18] Wang, X., Sun, X., Gong, F., et al. (2018) The Luohu Model: A Template for Integrated Urban Healthcare Systems in China. International Journal of Integrated Care, 18, 244. https://doi.org/10.5334/ijic.3955

[19] Zhu, J., Li, W. and Chen, L. (2016) Doctors in China: Improving Quality through Modernisation of Residency Education. The Lancet, 388, 1922-1929. https://doi.org/10.1016/S0140-6736(16)00582-1

[20] Xie, Z. and Zhang, J. (2018) New Directions in Health Sciences Libraries in China. Health Information \& Libraries Journal, 35, 165-169. https://doi.org/10.1111/hir.12215

[21] Kringos, D.S., Boerma, W., van der Zee, J., et al. (2013) Europe's Strong Primary Care Systems Are Linked to Better Population Health But Also to Higher Health Spending. Health Affairs, 32, 686-694. https://doi.org/10.1377/hlthaff.2012.1242

[22] World Health Organization (2018) Continuity and Coordination of Care: A Practice Brief to Support Implementation of the WHO Framework on Integrated People-Centred Health Services.

[23] Meng, Q., Xu, L., Zhang, Y., et al. (2012) Trends in Access to Health Services and Financial Protection in China between 2003 and 2011: A Cross-Sectional Study. The Lancet, 379, 805-814. https://doi.org/10.1016/S0140-6736(12)60278-5 